\title{
A REFORMA DO CONSELHO DE SEGURANÇA DAS NAÇÕES UNIDAS E A PERSPECTIVA BRASILEIRA
}

Luís Filipe de Miranda Grochocki ${ }^{1}$

\section{Resumo}

O objetivo geral deste estudo é apresentar as críticas quanto à reforma do Conselho de Segurança das Nações Unidas. Por sua vez, o objetivo específico é o de analisar a proposta brasileira de reforma. Inicialmente, apresenta-se um histórico da criação e do funcionamento do Conselho, possibilitando ao leitor a contextualização e a compreensão das críticas ao seu desempenho.

Enfoca-se, em um segundo momento, a importância do poder de veto para garantir a participação dos principais atores internacionais na ONU e sua relevância no debate da reforma. Conclui-se com a análise da reforma, esclarecendo as posições dos principais grupos de opinião e avaliando as propostas concretas apresentadas até o momento, enfatizando a perspectiva brasileira.

\section{Palavras-Chave}

Organização das Nações Unidas; Conselho de Segurança; Reforma; Política Internacional; Poder de Veto;

Observa-se nos últimos anos um movimento entre os Estados Membros da Organização das Nações Unidas (ONU) a favor de uma reforma que traga maior legitimidade, eficiência e transparência ao seu funcionamento.

Umas das reformas essenciais para que esses objetivos sejam alcançados é a do Conselho de Segurança das Nações Unidas (CSNU). Apesar de sua necessidade ter sido reconhecida por 147 Chefes de Estado e de Governo e pelos 191 Estados Membros, durante a Assembléia do Milênio (2000), essa vem sendo uma das reformas mais debatidas e controvertidas entre os Estados Membros, não tendo sido possível obter um consenso sobre o tema.

\footnotetext{
${ }^{1}$ Bacharel em Relações Internacionais e aluno do curso de Direito do UniCEUB.
} 
O Secretário-Geral das Nações Unidas (SGNU), Kofi Annan, um dos grandes defensores da reforma da Organização, reserva-se a salientar, como o fez em seu relatório "Strengthening of the United Nations: an agenda for further change" (2002), que a reforma das Nações Unidas só será completa com a conclusão da reforma do CSNU. ${ }^{2}$

O CSNU foi estabelecido em 1945, logo após o fim da II Guerra Mundial, possuía inicialmente 11 membros, sendo 5 membros permanentes e 6 membros não-permanentes de um total de 51 Estados Membros da ONU. Em 1965, em decorrência do grande aumento de membros, os assentos não-permanentes no CSNU foram aumentados para 10. Atualmente, a ONU é composta por 191 membros e o CSNU é representado por 15 delegações, não tendo sido ampliado o número de assentos desde 1965. Essa é uma das alegações da necessidade de reforma deste órgão. Outros sustentam que a composição atual não reflete as mudanças políticas e econômicas ocorridas nos últimos 60 anos e que o poder de veto poderia ser prejudicial à tomada de decisões. O movimento pela reforma busca, portanto, tornar o CSNU um órgão de tomada de decisões mais legítimo, eficiente e transparente.

Em 3 de dezembro de 1993, foi criado o Grupo de Trabalho sobre a reforma do CSNU, por meio da resolução ${ }^{\circ} 48 / 26$, com o intuito de facilitar o debate entre os Estados Membros. Entretanto, os doze anos de seu funcionamento têm sido caracterizados por poucos avanços ou, até mesmo, por total imobilismo.

Recentemente, tem-se verificado um aumento considerável das responsabilidades do Conselho de Segurança, principalmente no que diz respeito ao uso do Capítulo VII da Carta das Nações Unidas - intitulado "Ação relativa a ameaças à paz, ruptura da paz e atos de agressão". Dessa forma, para que esse órgão desempenhe eficazmente sua responsabilidade na manutenção da paz e segurança no século XXI, seu processo decisório deve ser fortalecido com a implementação de uma série de reformas que ampliem a legitimidade, eficiência e transparência desse.

Há expectativa de que até a Cúpula de Setembro, ou, mais tardar, o final de 2005, se avance a análise das propostas de reforma do CSNU e decisões concretas quanto à reforma possam ser alcançadas.

\footnotetext{
${ }^{2}$ United Nations. Strengthening of the United Nations: an agenda for further change. General Assembly. Report of the Secretary-General. 2002.
} 


\section{Situação problemática}

A Carta das Nações Unidas, iniciativa dos Estados Unidos (EUA), Reino Unido (RU) e União Soviética (URSS), foi esboçada em Durbarton Oaks, em 1944, e apresentada para exame pelas potências aliadas durante a Conferência de São Francisco, em 1945.

Entre as "Propostas de Dumbarton Oaks", que constituíram documento base na Conferência de São Francisco, estava a de que o Conselho de Segurança deveria possuir 11 assentos, sendo cinco para membros permanentes e seis para membros não-permanentes, com mandatos de dois anos, sem reeleição consecutiva. ${ }^{3}$

Os assentos permanentes seriam ocupados pelos três proponentes da Carta - EUA, RU e URSS -, pela China e, por insistência britânica, pela França. A ocupação dos assentos não-permanentes competiria à Assembléia Geral, sendo que cada Estado-Membro teria direito a um voto. ${ }^{4}$

O procedimento de votação dentro do CSNU foi regulamentado logo após Dumbarton Oaks, durante a Conferência de Criméia, em 1945, onde os representantes dos EUA, RU e URSS redigiram a "fórmula de Yalta", que garante aos membros permanentes o "direito de veto" - obrigatoriedade do voto afirmativo ou da abstenção dos membros permanentes - sobre questões não processuais.

Desde a Conferência de São Francisco, ouvem-se críticas e sugestões sobre a legitimidade, eficiência e transparência do processo decisório do Conselho. No entanto, a única transformação significativa ocorreu entre 1963 e 1965, quando, por meio de emenda à Carta, aprovada pela Assembléia Geral e ratificada pelos Estados Membros, ampliou-se de seis para dez o número de assentos para membros não-permanentes. ${ }^{5}$

A Carta, portanto, bem como o Sistema Nações Unidas, ainda é reflexo do cenário internacional enfrentado no pós Segunda Guerra Mundial. Com o passar dos anos, devido a mudanças na própria Organização, como o aumento do número de membros de 51 para 191 e a ampliação das atividades sob a responsabilidade da ONU - Operações de Manutenção

\footnotetext{
${ }^{3}$ Claude, Jr., Inis L. Swords into Plowshares: The Problems and Progress of International Organization. 4. ed. New York: Random House, 1971. p. 25, 59.

${ }^{4}$ Patriota, Antonio de Aguiar. O Conselho de Segurança após a Guerra do Golfo: A Articulação de um Novo Paradigma de Segurança Coletiva. Brasília: Instituto Rio Branco; Fundação Alexandre de Gusmão; Centro de Estudos Estratégicos, 1998. p. 19.

5 Ver resolução $n^{\circ} 1991$ (1963) da AGNU. Disponível em: < http://ods-dds-ny.un.org/doc/ RESOLUTION/GEN/NR0/186/66/IMG/NR018666.pdf?OpenElement >. Acesso em: 20 outubro 2003.
} 
de Paz -, e à evolução do cenário mundial - como o fim da Guerra Fria - esse desajuste da Carta ficou, ainda mais, acentuado à percepção de seus signatários. ${ }^{6}$ Desse modo, apesar de a dificuldade em se obter um consenso sobre "como" realizar a reforma, observa-se que é cada vez maior a concordância entre os Estados Membros de que algumas mudanças na Organização são inevitáveis, sobretudo, no que tange o processo decisório do Conselho de Segurança.

Questionamentos quanto à legitimidade, eficiência e transparência do processo decisório do CSNU e, até mesmo, quanto à necessidade desse órgão foram apresentados recentemente pela sociedade internacional ao deparar-se com a questão da invasão ao Iraque.

Diante do impasse entre os membros permanentes e não-permanentes sobre a aprovação de projeto de resolução que aprovasse a invasão ao Iraque, EUA e Reino Unido decidiram iniciar a ação contra o Iraque sem o aval do CSNU, o que gerou comoção mundial de que o sistema das Nações Unidas estava fadado à morte.

No entanto, assim como a bipolaridade da Guerra Fria paralisou o CSNU, mas não conseguiu desacreditá-lo, a crise iraquiana dividiu e debilitou-o, sem conseguir torná-lo dispensável. Assim sendo, em reconhecimento à importância e legitimidade do CSNU perante a comunidade internacional, os Estados Unidos, juntamente com os demais Estados Membros, têm demonstrado o desejo de que esse órgão assuma papel essencial na reconstrução do Estado iraquiano, como visto na adoção unânime da resolução $n^{\circ} 1483$, em 22 de maio de 2003, a qual havia sido introduzida pelo governo americano. ${ }^{7}$

Além disso, iniciada a invasão anglo-americana no Iraque, ficou claro ao governo americano e de seus aliados que, como declarado em documento oficial norte-americano (National Security Strategy), em setembro de 2002, "no nation can build a safer, better world alone".

Confirmou-se, dessa forma, que, apesar de a configuração atual do processo decisório do CSNU não permitir seu perfeito funcionamento, a existência desse órgão é essencial para a concretização da paz e segurança internacionais e, assim, torna-se

\footnotetext{
${ }^{6}$ Rivlin, Benjamin. UN Reform from the Standpoint of the United States. Tokyo: UN University Lectures 11. 1995. p. 3. Disponível em: < http://www.ciaonet.org/wps/rib01/index.html >. Acesso em: 02 outubro 2003.

7 Tharoor, Shashi. Why América Still Needs the United Nations. Foreign Affairs, set./out. 2003. p. 1. Disponível em: < http://www.foreignaffairs.org/ 20030901faessay82505/shashi-tharoor/why - america - still needs - the - united - nations.html >. Acesso em: 30 setembro 2003.
} 
importante o estudo de configurações que aumentem a legitimidade, eficiência e transparência de suas decisões.

\section{Poder de Veto - $O$ " $x$ " da questão}

A Carta das Nações Unidas, em seu Art. 27, parágrafos 2 e 3, declara que:

“... as decisões do Conselho de Segurança, em questões processuais, serão tomadas por um voto afirmativo de nove membros. As decisões do Conselho de Segurança, em todos os outros assuntos, serão tomadas por um voto afirmativo dos nove membros, inclusive os votos de todos os membros permanentes". 8

É reconhecido na Carta, dessa forma, o mecanismo da ONU mais condenado por seus membros até os dias atuais, conhecido por "poder de veto". 9

Vale ressaltar que, na verdade, a despeito da redação do Art. 27 da Carta apresentar a necessidade do voto afirmativo dos membros permanentes, assim como ocorrido nos órgãos da Liga das Nações, adotou-se na prática que a abstenção de um desses membros não seria considerada veto, tão somente um voto negativo o seria. Assim, ao votar uma resolução é necessário que se verifique não somente se o número de votos afirmativos é suficiente para aprová-la, mas, também, se dentre os votos negativos há o voto de algum dos membros permanentes. ${ }^{10}$

Como explicado anteriormente, o processo de votação do Conselho de Segurança, incluindo o poder de veto, foi delineado pelos Estados Unidos, Reino Unido e União Soviética durante a Conferência de Yalta, em fevereiro de $1945 .^{11}$

Esse mecanismo pré-concebido tornou-se, portanto, conhecido pelos demais Estados na Conferência de São Francisco, tendo rapidamente gerado um sentimento negativo entre seus participantes. Propagou-se entre as delegações presentes que as cinco

\footnotetext{
${ }^{8}$ Brasil. Ministério das Relações Exteriores. Departamento Consular e Jurídico. Divisão de Atos Internacionais. Coleção de Atos Internacionais. Carta das Nações Unidas. MRE, 1976. p. 55.

${ }^{9}$ Claude, Jr., Inis L. Op. Cit. p. 141.

${ }^{10}$ Claude, Jr., Inis L. Op. Cit. p. 141.

${ }^{11}$ Idem. p. 59.
} 
potências permanentes, ao invés de se embasarem na democracia internacional, estavam tentando se estabelecer como ditadores globais. Como descrito por Inis Claude, "At San Francisco, so the argument runs, the great powers forced their hegemony upon a world which had fondly, but vainly, hoped for the dawn of a new day of international equity and justice". ${ }^{12}$

Somando-se a essa crítica, havia o fato de que seria permitida a utilização do veto por um dos membros permanentes mesmo que esse estivesse envolvido diretamente na disputa, ${ }^{13}$ o que dificultaria ainda mais o avanço da eficiência desse órgão. ${ }^{14}$

No entanto, conforme apresentado por Claude, os fundadores da ONU, ao atribuírem o poder de veto às grandes potências, não queriam aumentar seu poder, e sim reconhecer na Carta a diferença de poder que já existia entre elas e os demais países. Afinal, temiam que a ONU pudesse sofrer do mesmo mal que consumiu a Liga das Nações, o qual seria o abandono ou a não participação de algumas das principais potências da época. $\mathrm{O}$ veto tornar-se-ia, assim, a garantia do compromisso dessas potências com a Organização. $^{15}$

Além disso, o poder de veto buscava aumentar a eficácia das decisões desse Conselho, pois a aprovação unânime dos cinco membros permanentes, potências nos campos econômico, militar e político, significaria que esses se comprometiam a apoiar as ações adotadas pela resolução, o que reforçaria o cumprimento dessas. Ademais, principalmente, ao adotar medidas coercitivas sob o Capítulo VII, o CSNU precisaria estar certo de que essas teriam o suporte das cinco potências para que esse órgão não tomasse decisões que não tivesse capacidade de cumprir, pois isso acarretaria somente em uma perda de eficácia. Afinal, essas potências não disponibilizariam seus recursos econômicos, políticos e militares se não estivessem de acordo com o que fora decidido. ${ }^{16}$

Cabe acrescentar, quanto à crítica de que os P5 poderiam vetar mesmo as questões em que estivessem envolvidos, que, segundo Claude, no caso de que um dos membros permanentes se tornasse um Estado agressor, o veto não seria um instrumento impeditivo,

\footnotetext{
${ }^{12}$ Idem. p. 72.

${ }^{13}$ Exceto em casos de resoluções sob o Capítulo VI, solução pacífica de controvérsias, e a respeito do parágrafo 3 do Art. 52, nos quais aquele que fizer parte da controvérsia deverá se abster. Brasil. Op. Cit. p. 55.

${ }^{14}$ Claude, Jr., Inis L. Op. Cit. p. 145.

${ }^{15}$ Claude, Jr., Inis L. Op. Cit. p. 72-73, 146.

${ }^{16}$ Idem. p. 146-147.
} 
visto que essa questão nem chegaria a ser debatida no Conselho, já que resultaria em uma guerra entre potências, independente do formato e funcionamento desse órgão. ${ }^{17}$

Dessa forma, apesar da impopularidade do poder de veto entre os participantes da Conferência de São Francisco, seus opositores tiveram que ceder às pressões das cinco potências e consentir a aprovação desse mecanismo, para que ameaças como a do Senador americano Tom Connally, de que sem o veto não haveria a organização, não se concretizassem. $^{18}$

Não obstante terem passado vinte cinco anos para que o veto fosse utilizado por todos os membros permanentes, tendo a delegação americana sido a última a fazer uso desse, em 17 de março de 1970, até essa data o número total de vetos já somava 115, havendo somente a URSS vetado 105 vezes. Destarte, a URSS passou a ser vista pela sociedade internacional como a principal barreira para o pleno funcionamento do Conselho de Segurança. ${ }^{19}$

Realmente, a URSS não conteve, nem moderou o uso do seu poder de veto. Deve-se observar, entretanto, o que motivou essa atitude. Devido ao conflito ideológico da Guerra Fria, apresentado no capítulo anterior, a URSS, por possuir poucos aliados, encontrava-se isolada na arena internacional, representando uma minoria no CSNU que poucas vezes conseguia o apoio da maioria dos membros desse órgão. Ao contrário, os demais membros do Conselho geralmente obtinham maioria tanto para aprovar quanto para derrubar uma proposta de resolução ${ }^{20}$, desse modo, não necessitavam do veto tão freqüentemente, mesmo assim, registrou-se, por diversas vezes, a ameaça do uso do veto por esses para pressionar o predomínio de seus interesses. ${ }^{21}$

Como pôde ser visto no decorrer da existência da ONU, o processo decisório do CSNU encontrou-se, por muitas vezes, completamente paralisado, o que acarretou em uma crítica cada vez maior ao mecanismo do veto. No entanto, é importante ressaltar que o veto

\footnotetext{
${ }^{17}$ Idem. p. 147-148.

${ }^{18}$ Idem. p. 72.

${ }^{19}$ Idem. p. 148.

${ }^{20}$ Deve-se recordar que dentre os temas dessas propostas de resolução encontrava-se a "adesão de novos membros à ONU”, que, principalmente, durante os primeiros cinco anos da organização, tornou-se alvo da disputa ideológica, fazendo com que a maioria dos estados capitalista rejeitasse os novos membros apoiados pela URSS e, por sua vez, que a URSS vetasse os novos membros apoiados pelos capitalistas. Claude, Jr., Inis L. Op. Cit. p. 90.

${ }^{21}$ Idem. p. 149-150.
} 
serviu para impedir a atuação da Organização em diversas situações que poderiam resultar em um conflito direto entre as grandes potências. ${ }^{22}$

Desse modo, diante do uso do veto, os demais membros do Conselho devem avaliar cuidadosamente as potenciais consequiências de suas decisões a respeito do tópico vetado, podendo optar por três posições distintas, abandonar a questão que gerou a controvérsia, buscar maneiras de implementar essa questão, independente da oposição encontrada, ou utilizar-se da diplomacia para negociar um consenso a respeito da questão. ${ }^{23}$

$\mathrm{O}$ veto, desse modo, não deve ser visto como uma barreira ao pleno funcionamento do CSNU, mas sim como um mecanismo de alerta que indica quando algum tema específico não reflete consenso entre as grandes potências.

\section{A reforma do Conselho de Segurança das Nações Unidas}

\section{1 - Os Grupos de Opinião}

Com o retorno do debate da reforma do Conselho de Segurança na década de 90, ficou clara a divergência de visões e posições sobre o tema entre os membros da ONU, no entanto, para que alguns interesses gerais fossem defendidos, alguns países começaram a defender posições conjuntas, formando diferentes grupos de opinião, podendo concentrar todos esses grupos em três principais, o like-minded, o coffee club e a maioria silenciosa. ${ }^{24}$

O like-minded é um grupo formado por países favoráveis à ampliação da composição do CSNU nas duas categorias de assentos, permanentes e não-permanentes, e ao equilíbrio da distribuição das vagas entre países desenvolvidos e em desenvolvimento. Apesar de concordarem nesses dois pontos, não conseguem chegar a um consenso a respeito dos outros fatores que envolvem uma proposta de reforma, como o número ideal de membros, a questão do veto e as modalidades de eleição. Integram esse grupo, dentre outros, a Alemanha, Angola, Austrália, Azerbaijão, África do Sul, Bahamas, Bielorússia, Bélgica, Bósnia-Herzegóvina, Brasil, Cabo Verde, Croácia, Cuba, Dinamarca, Eslovênia,

\footnotetext{
${ }^{22}$ Idem. p. 158.

${ }^{23}$ Idem. p. 158-159.

${ }^{24}$ Brasil. Ministério das Relações Exteriores. Departamento de Organismos Internacionais. Divisão das Nações Unidas. Reforma do Conselho de Segurança das Nações Unidas. MRE, 1976. p. 4.
} 
França, Guiana, Hungria, Índia, Irlanda, Japão, Namíbia, Nigéria, Paraguai, Romênia, Reino Unido, República Tcheca, Rússia e Timor-Leste. ${ }^{25}$

Dentre os diferentes grupos de opinião agregados ao like-minded temos a Comunidade dos Países de Língua Portuguesa ${ }^{26}$ e a Organização da Unidade Africana ${ }^{27}$, atualmente conhecida por Unidade Africana (UA) ${ }^{28}$. Apesar dos esforços da UA em alcançar uma posição conjunta, nem todos os membros comprometem-se à mesma proposta, sobretudo, aqueles que têm maior apoio internacional para preencher uma vaga permanente não-rotativa, como é o caso da África do Sul e da Nigéria, além desses, o Egito, por não acreditar que será contemplado com um assento permanente, prefere aderir ao coffee club. ${ }^{29}$

O coffee club é um grupo composto por países cujo único interesse em comum é o desejo de impedir avanços no debate da ampliação dos assentos permanentes. Dentre os diversos países encontrados nesse grupo temos aqueles que não querem a reforma ou que querem somente a ampliação dos assentos não-permanentes por desejarem ocupar assento permanente e não acreditarem que obteriam êxito. Costumam apoiar a chamada fall-back position $^{30}$, defendida pelo Movimento Não-Alinhado, e a dissociação da ampliação do Conselho da questão do veto e dos métodos de trabalho. Integram esse grupo, entre outros, a Argentina, Canadá, China, Colômbia, Egito, Gana, Indonésia, Itália, México, Paquistão, República da Coréia, San Marino, Turquia e Zimbábue.

\footnotetext{
${ }^{25}$ Idem. p. 12.

${ }^{26}$ Foro multilateral, criado em 17 de julho de 1996, com o intuito de aprofundar a amizade mútua e a cooperação entre seus membros, os quais são: Angola, Brasil, Cabo Verde, Guiné-Bissau, Moçambique, Portugal, São Tomé e Príncipe e Timor-Leste. Comunidade dos Países de Língua Portuguesa. Disponível em: $<$ http://www.cplp.org >. Acesso em: 01 novembro 2003.

27 Organização criada com o intuito de livrar o Continente Africano dos vestígios da colonização e do apartheid, promover a união e a solidariedade entre os países africanos, coordenar e intensificar a cooperação para o desenvolvimento da região, proteger a soberania e a integridade territorial de seus membros e promover cooperação internacional por meio das Nações Unidas. African Union. Introduction. Disponível em: < http://www.africa-union.org/home/Welcome.htm >. Acesso em: 01 novembro 2003.

${ }^{28}$ Em 9 de setembro de 1999, os Chefes de Estado e de Governo da Organização da Unidade Africana adotaram a Declaração de Sirte, a qual clamava o estabelecimento da Unidade Africana com o propósito de acelerar o processo de integração do continente, permitindo que atuasse mais intensamente na economia global e que pudesse corresponder aos problemas sociais, econômicos e políticos causados pela globalização. É composta, atualmente, por 52 membros. African Union. Op. Cit.

${ }^{29}$ Brasil. Ministério das Relações Exteriores. Departamento de Organismos Internacionais. Divisão das Nações Unidas. Reforma do Conselho de Segurança das Nações Unidas. Op. Cit. p.11.

${ }^{30}$ Posição a qual prefere que a reforma se restrinja somente ao número de assentos não-permanentes, caso não seja possível obter um acordo sobre a expansão do Conselho em ambas categorias. Idem. p. 12.
} 
A maioria silenciosa é um grupo de países que prefere demonstrar neutralidade quanto à discussão do tema, por não possuírem grandes interesses ou para não desgastar suas relações com os demais países interessados no assunto. Sua preocupação reside, principalmente, na questão do veto, a qual possui duas vertentes, a limitação do exercício do veto pelos cinco membros permanentes originais e a extensão desse direito aos eventuais novos membros permanentes. Avança-se, cada vez mais, entre os membros desse grupo, a percepção de que a única opção viável à ampliação do Conselho é o aumento somente dos assentos não-permanentes.

Mesmo com a tentativa de formação desses grupos de opinião sobre a reforma, ainda não foi possível a nenhum desses obter número suficiente para adotar qualquer resolução ou decisão sobre o assunto, afinal, como ficou estabelecido na resolução $n^{\circ} 53$, de 23 de novembro de 1998, é necessário o voto afirmativo de, pelo menos, dois terços dos membros da Assembléia-Geral para qualquer aprovação a esse respeito.

\section{2 - As propostas de reforma do Conselho de Segurança}

As propostas de reforma do Conselho de Segurança apresentadas pelos Estados Membros, em decorrência das diferentes visões e posições a respeito desse tema, são diversas e, muitas vezes, contraditórias. Desse modo, cabe ao Grupo de Trabalho agrupálas, revisá-las e apresentá-las aos membros da ONU em seu informe anual à Assembléia.

\subsection{1 - A questão do veto}

Como dito anteriormente, há Estados que são a favor do poder de veto e outros que são contra esse mecanismo.

Os que são favoráveis tentam mantê-lo conforme criado, buscando evitar o debate sobre esse mecanismo ou, no máximo, aconselhar aos membros que possuem tal poder a reduzir o seu uso.

Por outro lado, aqueles que são contrários ao veto buscam restringir sua prática e até mesmo eliminá-lo por completo, requerendo, para tanto, que alguns artigos da Carta sejam modificados. 
Apesar de que caso uma dessas tentativas de limitar e eliminar o poder de veto fosse aprovada, certamente, acarretaria em uma maior eficiência na tomada de decisões do Conselho, é pouca a probabilidade de que alguma alteração à Carta sobre o veto seja implementada em um futuro próximo, ${ }^{31}$ pois, como explicado anteriormente, não se sabe o quanto isso afetaria o compromisso dos membros permanentes originais com as resoluções aprovadas contra a sua vontade e, até mesmo, quais poderiam ser as consequiências de tal desaprovação, o que leva ao questionamento, por parte de alguns membros, se, realmente, compensaria alterar esse mecanismo.

Ademais, sobretudo, no que tange as propostas de eliminação do direito do veto, por necessitarem de emendas à Carta para serem implementadas, demandariam a aprovação dos membros permanentes atuais que, até o momento, recusam-se a perder esse direito.

\subsection{2 - A busca por um Conselho de Segurança representativo e democrático}

As propostas de ampliação e distribuição de novos assentos do CSNU podem ser divididas em dois grupos principais, aquelas que apóiam o aumento de ambas as categorias e aquelas que apóiam o aumento somente da categoria de membros não-permanentes.

As propostas do primeiro grupo podem ser divididas, ainda, entre as que são contra a extensão do poder de veto aos novos membros permanentes e as que são favoráveis a direitos iguais a todos os membros permanentes enquanto essa prerrogativa existir. Além disso, entre essas propostas verificam-se diferenças quanto ao funcionamento dos novos assentos permanentes, se esses serão reservados a presença de Estados específicos ou se serão designados a regiões específicas e preenchidos por meio de sistema rotativo.

Quanto às propostas do segundo grupo, há as que são a favor de uma ampliação somente das cadeiras não-permanentes, em um primeiro momento, e, em seguida, de uma ampliação permanente e há as que discordam completamente que deva ocorrer uma expansão dos assentos permanentes.

Dentro desses dois grupos maiores há, ademais, divergências quanto à melhor forma de distribuir os novos assentos, se entre desenvolvidos e em desenvolvimento, por região

\footnotetext{
${ }^{31}$ Sutterlin, James S. United Nations Decisionmaking: Future Iniciatives for the Security Council and the Secretary-General. Weiss, Thomas G. (Ed.). Collective Security in a Changing World: A World Peace Foundation Study. Lynne Rienner Publishers. Boulder \& London. 1993. (Emerging Global Issues). p. 130.
} 
geográfica ou aplicando essas duas formas de distribuição e quanto ao número total de membros do Conselho e de votos afirmativos necessários para aprovar uma decisão.

No que diz respeito à configuração atual do CSNU, é grande o número de críticas, geralmente abordando sua falta de representatividade e democracia, como pode ser visto em declaração de James Sutterlin:

\begin{abstract}
"The present Five Permanent Members do not represent either the five most powerful countries in the world or the regions of the world where conflict is most likely to occur. At a time of expanding democracy, the Security Council thus constitutes a distinctly undemocratic institution. It is not well structured enough to enjoy full confidence of the majority of members states." 32
\end{abstract}

A ampliação e distribuição eqüitativa dos assentos do CSNU tornariam, dessa maneira, o órgão mais representativo, democrático e, conseqüentemente, mais legítimo perante a comunidade internacional.

Cada vez mais essa passa a ser a percepção dos membros da ONU, pois, como demonstrou o Embaixador brasileiro, José M. Bustani, "há dez anos era difícil falar sobre isso, mas a situação começou a mudar e já se fala na ampliação de membros permanentes". ${ }^{33}$ A conclusão desse processo, contudo, deve ser vista como um objetivo de médio a longo prazo, afinal, todas as propostas devem ser muito bem discutidas e avaliadas porque dependendo da amplitude do novo Conselho, da forma como serão preenchidas as vagas ou da extensão do poder de veto aos novos membros permanentes poderá haver uma diminuição significativa da eficiência na tomada de decisões desse órgão.

\title{
3.2.3 - A perspectiva brasileira
}

Em 2003, Kofi Annan renovou o desejo de discutir a reforma por meio da convocação de um grupo de especialistas para analisar e propor soluções aos problemas

\footnotetext{
${ }^{32}$ Sutterlin, James S. Op. Cit. p. 130.

${ }^{33}$ Bustani, José M. Por uma ONU plural. ISTOÉ, São Paulo, n.1769, p. 10, 27 agosto 2003. Entrevista concedida a Hélio Contreiras.
} 
enfrentados pela Organização. Na divulgação de seu relatório "Uma Liberdade mais Ampla: Rumo à Segurança, Desenvolvimento e Direitos Humanos para Todos”, em abril de 2005, o SGNU apresentou propostas a serem avaliadas pelos Estados Membros. Quanto ao CSNU, o SGNU declarou o desejo de solucionar o tema até a Cúpula de Setembro de 2005, acreditando que com a conclusão dessa reforma, a pauta de reformas ganharia maior agilidade.

De acordo com o relatório do Painel de Alto Nível, há duas propostas quanto à reforma do CSNU, ambas visando a ampliação para o total de 24 Estados Membros: a primeira, consiste na distribuição de seis novos assentos permanentes, sem direito a veto, e 3 não-permanentes entre países da África, Américas, Ásia e Europa; a segunda, corresponde à criação de oito assentos de quatro anos, com direito à reeleição, e 1 nãopermanente.

Ao notar o desejo do SGNU em dar andamento ao processo de reforma do CSNU, os Estados do Brasil, Índia, Japão e Alemanha, que haviam recentemente formado o G4 grupo de Estados com intenções de ocupar assento permanente no CSNU -, agilizaram a negociação de novo projeto de resolução a respeito da reforma do Conselho. A proposta consiste no aumento do número de membros do CSNU para 25, acrescentando seis novos membros permanentes (dois da África, dois da Ásia, um da América Latina e Caribe e um da Europa Ocidental e outros Estados) e quatro não-permanentes (um da África, um da Ásia, um da Europa Oriental e um da América Latina e Caribe). A eleição ocorreria até três semanas após a aprovação da resolução, por dois terços dos votos dos Estados Membros. Os novos membros permanentes ocupariam os assentos sem o poder de veto até que essa questão fosse discutida e as emendas à Carta das Nações Unidas seriam reavaliadas 15 anos depois de entrarem em funcionamento. ${ }^{34}$

O projeto de resolução, enumerado A/59/L.64, foi apresentado pelo Embaixador brasileiro, Ronaldo Sardenberg, no dia 6 de julho, com o apoio de 27 Estados Membros, incluídos França e os membros do G4.

Apesar do recebimento positivo do projeto por outros Estados, como alguns membros da Unidade Africana, China e Estados Unidos logo demonstraram oposição,

\footnotetext{
${ }^{34}$ Ver projeto de resolução A/59/L.64 da AGNU. Disponível em: < http://www.un.org/Docs/journal/asp/ ws.asp?m=a/59/L.64 >. Acesso em: 10 agosto 2005.
} 
criando informalmente o grupo "Uniting for Consensus", com a justificativa de que a reforma deve ser objeto de consenso para evitar divisões na Organização.

Os Estados Unidos, após um longo período de silêncio quanto à sua posição a respeito da reforma, resolveu declarar, no dia 12 de julho, que concorda com a expansão do número de membros do CSNU para 19 a 20, admitindo a inclusão do Japão entre os membros permanentes, mas somente após a realização da reforma dos outros órgãos da ONU.

Em seguida, apresentou-se novo projeto de resolução denominado "Uniting for Consensus", apoiado por membros do Coffee Club, que mantém os 5 assentos permanentes e amplia para 20 o número de não-permanentes, reelegíveis.

Por fim, a mais recente proposta de reforma do Conselho consiste na adição de 1 assento não-permanente rotativo (entre países da África, Ásia, América Latina e Caribe) à proposta do projeto de resolução A/59/L.64. A proposta foi alcançada por meio de negociações entre o G4 e membros da Unidade Africana, entretanto, não deve seguir adiante, pois não há homogeneidade na decisão dos membros da UA.

O Brasil, portanto, tem até o final de 2005 para aproveitar o incentivo do SGNU em dar andamento à reforma e arrecadar apoio suficiente para a aprovação de um projeto de resolução ou terá que esperar por outra oportunidade futura que provavelmente demorará a surgir. Afinal, o SGNU, Kofi Annan, maior defensor da reforma da Organização, está terminando o mandato e demonstra querer deixar como marco a reestruturação do CSNU, assim, não poupará esforços para concluir o processo antes de sua saída.

Ademais, observa-se o desejo intenso da liderança do governo brasileiro em alcançar um assento permanente no CSNU, o mais rápido possível, não somente para afirmar a posição de potência regional, mas também para que essa vitória internacional tenha projeção nacional e fortaleça o governo em uma tentativa de reeleição, assim, a candidatura brasileira a membro permanente perderia certa importância após o período eleitoral no país.

Há, então, a intenção de apresentar um projeto "forçado" de reforma do CSNU, tanto de autoridades internacionais quanto nacionais, para que interesses outros que maior legitimidade, eficiência e transparência sejam obtidos. Certamente, caso se prossiga desse 
modo, acarretará no veto de algum dos atuais membros permanentes, o que resultará um desgaste maior ao tema.

\section{4 - Conclusão}

Nesse artigo, verificou-se que a ONU, juntamente com seus órgãos e agências, por ser composta por Estados e interagir com outros atores internacionais, é reflexo da realidade enfrentada no cenário internacional.

Pôde-se observar, no decorrer dos anos, que o Conselho de Segurança enfrentou variações no grau de legitimidade, eficiência e transparência de suas decisões, dependendo do contexto internacional da época e, conseqüentemente, da disposição dos Estados Membros em cooperar em favor de um objetivo comum.

Não obstante, alterações na estrutura do Conselho de Segurança mediante um procedimento de reforma poderiam auxiliar na obtenção de um processo decisório mais legítimo, eficiente e transparente.

Assim, apesar das dificuldades e da demora em obter avanços no debate sobre a reforma do Conselho de Segurança das Nações Unidas, espera-se a continuação do processo de reforma desse órgão e a intensificação dos debates a esse respeito com vistas a avançar na análise de propostas viáveis.

Sugere-se, para a reforma do CSNU, que se restrinja o poder de veto somente às questões relacionadas ao Capítulo VII da Carta das Nações Unidas, que se ampliem ambas as categorias de assentos, totalizando, no máximo, vinte e um membros, o que demandaria uma maioria de 13 votos afirmativos (cerca de $60 \%$ dos votos) para adotar decisões. A distribuição dos novos assentos deveria ser eqüitativa, considerando tanto os critérios regionais quanto econômicos - desenvolvidos e em desenvolvimento.

Conclui-se este artigo, com a reiteração de que, apesar de todas as dificuldades inerentes ao debate sobre a reforma do Conselho de Segurança, é válido o esforço em discutir e implementar alterações no órgão. A atualidade do debate demonstra o compromisso dos atores internacionais interessados em dispor de um órgão decisório munido de crescente legitimidade, eficiência e transparência na busca pela manutenção da 
paz e da segurança internacional, motivos que presidiram à criação da Organização das Nações Unidas e que não devem ser colocados sob interesses particulares.

\section{Referências Bibliográficas}

ARAUJO, Luis Ivani de Amorim. Das Organizações Internacionais. Rio de Janeiro: Forense, 2002.

BARBOSA, Rubens Antônio. Os Estados Unidos pós 11 de setembro de 2001: implicações para a ordem mundial e para o Brasil. Revista Brasileira de Política Internacional. Brasília: IBRI, ano 45, n. 1, p. 72-91, jan./jun. 2002.

BERTRAND, Maurice. A ONU. Tradução de Guilherme João de Freitas Teixeira. Petrópolis: Vozes, 1995.

. The Historical Development of Efforts to Reform the UN. Roberts, Adam; Kingsbury, Benedict (Ed.). United Nations, Divided World: The UN's roles in International Relations. 2. ed. Oxford: Clarendon Press. 1993.

BRASIL. Ministério das Relações Exteriores. Departamento Consular e Jurídico. Divisão de Atos Internacionais. Coleção de Atos Internacionais. Carta das Nações Unidas. MRE, 1976.

. Ministério das Relações Exteriores. Departamento de Organismos Internacionais. Divisão das Nações Unidas. Reforma do Conselho de Segurança das Nações Unidas. MRE, 2003.

BUSTANI, José M. Por uma ONU plural. ISTOÉ, São Paulo, n.1769, p. 10, 27 agosto 2003. Entrevista concedida a Hélio Contreiras.

CHOMSKY, Noam. 11 de setembro. Tradução de Luiz Antonio Aguiar. 5. ed. Rio de Janeiro: Bertrand Brasil, 2002.

CLAUDE, Jr., Inis L. Swords into Plowshares: The Problems and Progress of International Organization. 4. ed. New York: Random House, 1971.

FONSECA, Jr., Gelson. A legitimidade e outras questões internacionais. São Paulo: Paz e Terra, 1998.

FONTOURA, Paulo Roberto Campos Tarrisse da. O Brasil e as Operações de Manutenção da Paz das Nações Unidas. Brasília: FUNAG, 1999.

GARCIA, Eugênio Vargas. O Brasil e a Liga das Nações (1919-1926): vencer ou não perder. Porto Alegre/Brasília: Ed. Da Universidade/UFRGS/Fundação Alexandre de Gusmão/FUNAG, 2000.

KEOHANE, Robert O.; NYE, Jr., Joseph S. Power and Interdependence. 3. ed. Longman. 2001.

MOREIRA, Adriano. Teoria das Relações Internacionais. Coimbra: Livraria Almedina, 1999. 
NATIONS UNIES. Resolutions adoptées par l'Assemblée Générale à sa Huitieme session pedant la période du 15 septembre au 9 décembre 1953. Assemblée Générale. Documents Officiels. Dixieme session. Supplement nº 17 (A/2630). New York. 1953.

. Resolutions adoptées par l'Assemblée Générale au cours de sa dixieme session. 20 septembre - 20 décembre 1955. Assemblée Générale. Documents Officiels. Dixieme session. Supplement n ${ }^{\circ} 19$ (A/3116). New York. 1955.

PATRIOTA, Antonio de Aguiar. O Conselho de Segurança após a Guerra do Golfo: A Articulação de um Novo Paradigma de Segurança Coletiva. Brasília: Instituto Rio Branco; Fundação Alexandre de Gusmão; Centro de Estudos Estratégicos, 1998.

SARAIVA, José Flávio Sombra (Org.). Relações Internacionais - dois séculos de história: entre a preponderância européia e a emergência americano-soviética (1815-1947) Volume I. Brasília: IBRI, 2001.

(Org.). Relações Internacionais - dois séculos de história: entre a ordem bipolar e o policentrismo (de 1947 a nossos dias) - Volume II. Brasília: IBRI, 2001.

SEITENFUS, Ricardo A. S. Manual das Organizações Internacionais. 2. ed. rev. amp. Porto Alegre: Livraria do Advogado, 2000.

SUTTERLIN, James S. United Nations Decisionmaking: Future Iniciatives for the Security Council and the Secretary-General. Weiss, Thomas G. (Ed.). Collective Security in a Changing World: A World Peace Foundation Study. Lynne Rienner Publishers. Boulder \& London. 1993. (Emerging Global Issues).

UNITED NATIONS. Resolutions and Decisions of the Security Council. Security Council. Official Records. First Year. 1946.

. Strengthening of the United Nations: an agenda for further change. General Assembly. Report of the Secretary-General. 2002.

Resolutions and Decisions of the Security Council. Security Council. Official Records. Second Year. 1947.

WIGHT, Martin. A Política do Poder. Tradução de Carlos Sérgio Duarte. 2. ed. Brasília: Editora Universidade de Brasília, Instituto de Pesquisa de Relações Internacionais; São Paulo: Imprensa Oficial do Estado de São Paulo, 2002.

Artigos e Sites

AFRICAN UNION. Introduction. Disponível em: < http://www.africa-union.org/ home/Welcome.htm >. Acesso em: 01 novembro 2003.

BLASEY, Bassim. Open-Ended Working Group On The Question Of Equitable Representation On And Increase In The Membership Of Security Council And Other Matters Related To The Security Council. Disponível em: < http://www.australiaun.org/Statements/UNGA\%2056/Peace\%20and\%20Security/020311

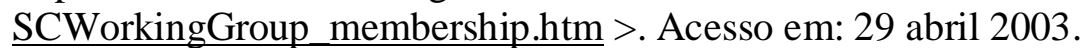


BRASIL. Ministério das Relações Exteriores. Organismos Regionais. Grupo do Rio. Disponível em: < $\quad$ http://www.mre.gov.br/cdbrasil/itamaraty/web/ port/relext/mre/orgreg/gruporio/ > . Acesso em: 04 novembro 2003.

COMMONWEALTH SECRETARIAT. The Commonwealth. Disponível em: < http://www.thecommonwealth.org/whoweare/comm.html >. Acesso em: 17 outubro 2003.

COMUNIDADE DOS PAÍSES DE LÍNGUA PORTUGUESA. Disponível em: < http://www.cplp.org >. Acesso em: 01 novembro 2003.

GLENNON, Michael J. Why the Security Council Failed. Foreign Affairs, mai./jun. 2003. Disponível em: < http://www.foreignaffairs.org/ 20030501faessay11217/michael-jglennon/why-the-security-council-failed.html >. Acesso em: 10 maio 2003.

HAYNES, Lukas; IGNATIEFF, Michael. Mobilizing Public Support for the United Nations: A case study of State Department leadership in building public and congressional support for a leading U.S. role in International Organization, 1944-1945. Disponível em: < http://www.ksg.harvard.edu/leadership/Pdf/ HaynesIgnatieffWorkingPaper.pdf >. Acesso em: 15 setembro 2003.

ISRAEL. Ministry of Foreign Affairs. From mandate to independence. Disponível em: < http://www.mfa.gov.il/mfa/go.asp?MFAH01dm0 >. Acesso em: 15 setembro 2003.

JAPÃO. The Ministry of Foreign Affairs of Japan. Security Council Reform. Disponível em: $\langle$ http://www.mofa.go.jp/policy/un/reform/role21.html $>$. Acesso em: 16 maio 2003.

LUCK, Edward C., et al. Stayin Alive: The Rumors of the UN`s Death Have Been Exaggerated. Foreign Affairs, jul./ago. 2003. Disponível em: < http://www.foreignaffairs.org/20030701 faresponse82417/edward-c-luck/stayin-alive-therumors-of-the-un-s-death-have-been-exaggerated.html >. Acesso em: 30 setembro 2003.

NACIONES UNIDAS. Evolución de los procedimientos del Consejo de Seguridad en 2001. Consejo de Seguridad. 2002. Disponível em: < http://www.cinu.org.mx/onu/reforma cs/reforma cs doctos.htm >. Acesso em: 27 agosto 2005.

. Informe del Grupo de Trabajo de composición abierta sobre la cuestión de la representación equitativa en el Consejo de Seguridad y del aumento del número de sus miembros y otros asuntos relativos al Consejo de Seguridade (A/57/47). Asamblea General. Documentos Oficiales. Quincuagésimo séptimo período de sesiones. Suplemento $\mathrm{N}^{\circ} 47$. Nueva York. 2003. Disponível em: < http://www.cinu.org.mx/onu/reforma cs/a48 47.pdf >. Acesso em: 27 agosto 2005.

NON-ALIGNED MOVEMENT. Background. Disponível em: < http://www.nam.gov.za/background/history.htm >. Acesso em: 20 outubro 2003.

RIVLIN, Benjamin. UN Reform from the Standpoint of the United States. Tokyo: UN University Lectures 11. 1995. Disponível em: < http://www.ciaonet.org/ wps/rib01/index.html >. Acesso em: 02 outubro 2003.

THAROOR, Shashi. Why América Still Needs the United Nations. Foreign Affairs, set./out. 2003. Disponível em: < http://www.foreignaffairs.org/ 20030901faessay82505/shashi- 
tharoor/why - america - still - needs - the - united - nations.html >. Acesso em: 30 setembro 2003.

UNITED NATIONS. Repertory of Practice of United Nations Organs. Supplement N 6 (1979-1984). Volume III. 1995. Disponível em: < http://untreaty.un.org/cod/repertory/ art23/english/rep_supp6_vol3-art23_e_advance.pdf >. Acesso em: 21 outubro 2003. 